\section{AN EFFECT OF SPRAY CONFIGURATION AND ADSORBENT MATERIAL ON PERFORMANCE OF THE SPRAY SCRUBBER IN THE DOWNDRAFT GASIFIER-ENGINE SYSTEM}

\author{
A. A. P. Susastriawana*, Yuli Purwantoa, Purnomoa, Kade Vindob, \\ Adi Hariyantob
}

aDepartment of Mechanical Engineering, Faculty of Industrial Technology, Institut Sains \& Teknologi AKPRIND, Indonesia bundergraduate Student, Department of Mechanical Engineering, Faculty of Industrial Technology, Institut Sains \& Teknologi AKPRIND, Indonesia
Article history

Received

3 April 2021

Received in revised form

26 August 2021

Accepted

19 September 2021

Published Online

20 October 2021

*Corresponding author agung589E@akprind.ac.id

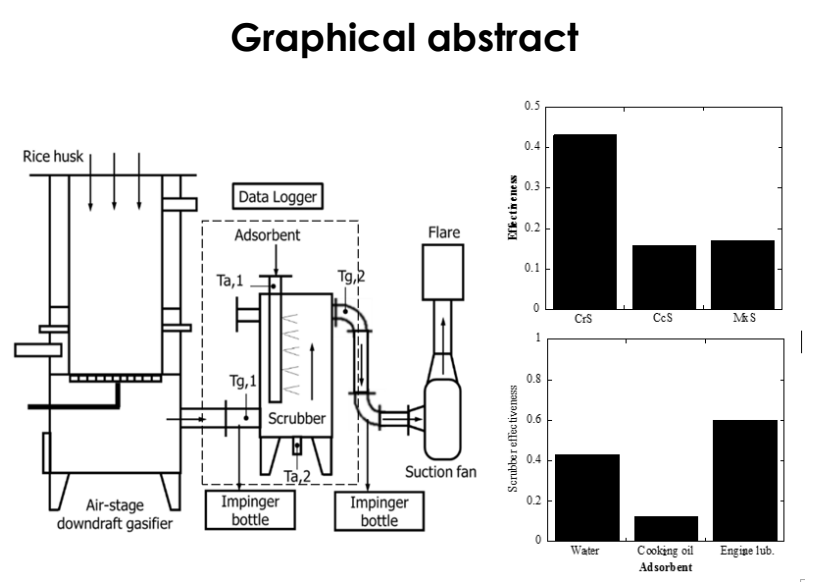

\begin{abstract}
The work aims to investigate an effect of spray configuration and adsorbent material on performance of wet scrubber in removing tar gravimetric in producer gas. The scrubber is installed at small scale downdraft gasifier-engine system and the tests are conducted in two sections. Firstly, the scrubber is tested using water adsorbent at various spray flow configurations to the producer gas flow (cross flow, counter flow, mixed flow). Secondly, the scrubber is tested using adsorbent of cooking oil and waste of engine lubricant at cross flow spray configuration. The performance of the scrubber investigated are temperature profile, log mean temperature difference, heat transfer rate, and tar removal effectiveness. For spray configuration test, the result shows that cross spray configuration (CrS) has the optimum performance. The CsS scrubber has the highest LMTD, heat transfer rate, and tar removal efficiency among others. The values are $29.8^{\circ} \mathrm{C}, 7.84 \mathrm{~kW}$, and 0.43 , accordingly. Meanwhile, the test using different adsorbent indicates adsorption property of the adsorbent plays an important rules in tar removal effectiveness of the scrubber. The removal effectiveness of the scrubber for using adsorbent of water, cooking oil, and engine lubricant are 0.43, 0.12, and 0.60, respectively.
\end{abstract}

Keywords: Gasifier, producer gas, spray, scrubber, tar

(C) 2021 Penerbit UTM Press. All rights reserved

\subsection{INTRODUCTION}

Biomass gasification is very promising technology in converting dry biomass waste into gaseous fuel "producer gas". The technology is considered to be one of the most effective methods for upgrading the biomass fuel [1]. Various biomass wastes have been used as a feedstock in gasification system, such as rice husk $[2,3,4]$, wood chip $[5,6,7]$, corn stalk [8], oil palm fronds [9], and many others. Combustion of a producer gas from gasification is cleaner than direct combustion of the biomass [10]. Producer gas can 
be used as fuel of a burner or as fuel of internal combustion (IC) engine.

Common problem in utilization of producer gas from biomass gasification as a fuel of IC engine is tar content. Tar is a mixture of condensable hydrocarbons, including aromatic compounds with up to five rings (which can be oxygenated) as well as Polycyclic Aromatic Hydrocarbons (PAHs) [11, 12]. The tar has corrosive property, thus it is prohibited to direct use of the producer gas as fuel of IC engine [13]. In order to utilize a producer gas as a fuel of IC engine, tar content in a producer gas must be less than $100 \mathrm{mg} / \mathrm{Nm}^{3}$ [14]. High tar content in the producer gas may block and contaminate the fuel line and damage the engine for long term use [15]. It is very important task to remove or at least reduce tar content in the producer gas till tar content below 100 $\mathrm{mg} / \mathrm{Nm}^{3}$.

Many tar removal methods have been reported and successfully used to remove tar content in the producer gas. Tar removal can be performed inside the gasifier or at downdstream of the gasifier. The first method is called a primary method and the second one is named a secondary method [11, 16]. The secondary method can be performed by hot and cold gas treatment, such as spray and wash towers, venturi scrubbers, wet electrostatic precipitators or cyclones. Due to simplicity in construction and operation, low pressure drop, and low cost investment, the scrubber is widely used in gasifierengine system. Depending on scrubbing material used, scrubber can be categorized as wet and dry scrubber. In wet scrubber, liquid is used as scrubbing material. On the other hand, solid is used as scrubbing material in dry scrubber. Further, wet scrubber can be approached with impingement, spray, and venturi scrubber as shown in Figure 1. A producer gas is impinged to the adsorbent in the vessel of impingement scrubber. Tar condenses when contact with the adsorbent and dissolves to the adsorbent. In spray scrubber, a producer gas flows upward and an adsorbent is spread in opposite direction. Meanwhile, a producer gas is injected into the adsorbent flow in venturi scrubber. Various adsorbents, such as water [17, 18], waste palm oil [19], vegetable oil [18, 20], diesel fuel, biodiesel fuel, and engine oil [20] have been used.

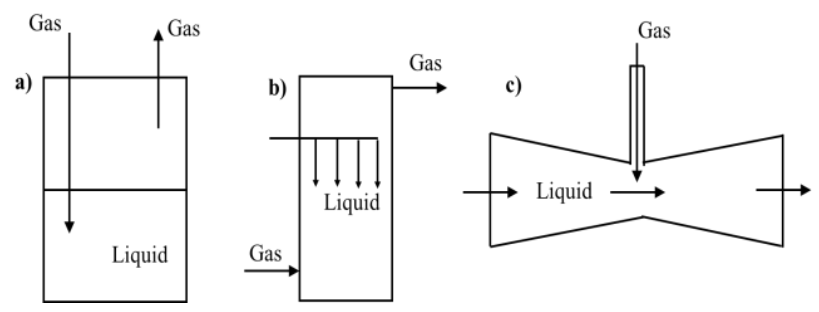

Figure 1 Schematic diagram of different type of wet scrubber: (a) Impingement, b) Spray, and c) Venturi
Differ from impingement scrubber, spray scrubber is less common being used in gasification system. Typically, the spray scrubber has counter flow configuration, i.e. the producer gas flows upward and the adsorbent spreads in opposite direction. This type of scrubber requires a pump to circulate the adsorbent from a reservoir to a scrubber vessel. In principle, the spray scrubber is a cooling tower where heat transfer between producer gas and adsorbent occurs. Cooling tower is widely used due to its characteristics, i.e. high efficiency of heat exchange, small size and less energy consumption [21]. It was observed that spray cooling efficiency was affected by spray coverage area, gas stream velocity, and droplet size. At the same droplet size, the lower the air velocity is, the more cooling is achieved. Lower air velocity means larger coverage area because the time for droplets to lose momentum and follow the air stream is longer, which results in a better coverage area [22]. The radial spray pattern of individual nozzle of counter flow cooling tower generated the best possible thermal performance [23]. The effective cooling tower requires the careful arrangement of the spray nozzle, since the performance of the cooling tower highly depends on the direction injection of the nozzle [24].

In order to analyze heat transfer between the producer gas and the adsorbent, the scrubber is assumed as counter flow double pipe heat exchanger. According to Cengel \& Turner [25], cold fluid (adsorbent) adsorbs heat from hot fluid (producer gas), thus the temperature of cold fluid increases and vice versa. Heat adsorbs by cold fluid can be calculated using Eq. (1). Meanwhile, the temperature different between hot fluid and cold fluid entering and leaving the heat exchanger is defined as log mean temperature different (LMTD) and calculated using Eq. (2).

$$
\begin{aligned}
& Q=\dot{m} \times c_{p} \times\left(h_{o}-h_{l}\right) \\
& L M T D=\frac{\Delta T_{1}-\Delta T_{2}}{\ln \left(\frac{\Delta T_{1}}{\Delta T_{2}}\right)}
\end{aligned}
$$

Where $m$ is the mass flow rate of the adsorbent $\left(\mathrm{m}^{3} / \mathrm{s}\right)$, $\mathrm{C}_{\mathrm{p}}$ is the specific heat of the adsorbent $\left(\mathrm{J} / \mathrm{kg} .{ }^{\circ} \mathrm{K}\right)$, ho and hi are the exit and inlet temperature of the cold fluid, $\Delta T_{1}=T_{h, i}-T_{c, o}$ and $\Delta T_{2}=T_{h, o}-T_{c, i}$.

Meanwhile, effectiveness of the scrubber is defined as an ability of the scrubber in reducing tar content of producer gas. Higher the effectiveness of the scrubber, better the performance of the scrubber. Tar removal effectiveness of the scrubber is obtained using Eq. (3).

$$
\eta_{S}=\frac{T C_{\text {in }}-T C_{\text {out }}}{T C_{\text {in }}}
$$

where $\eta_{s}$ is the tar removal effectiveness of the scrubber, $\mathrm{TC}_{\text {in }}$ and $\mathrm{TC}_{\text {out }}$ are the tar content at inlet and outlet of the scrubber, respectively. 
In biomass gasification, the use of spray scrubber is still limited and only the counter flow spray scrubber has been applied so far. Neither cross flow nor mixed flow spray scrubber have been used as tar removal component in gasifier system so far. Thus, the present work aims to investigate an effect of spray configuration (cross spray, counter spray, and mixed spray) and adsorbent material on thermal characteristics and tar removal effectiveness of the spray scrubber installed at the small-scale air-stage downdraft gasifier system.

\subsection{METHODOLOGY}

Figure 2 shows a photograph and schematic diagram of an experimental setup in the present work. The setup consisted of an air-stage downdraft gasifier, blower, water spray scrubber, suction fan, flare, and measurement devices (K-Type Thermocouples, Data Logger Graphtec GL 240, Rotameter, and Impinging Bottle).
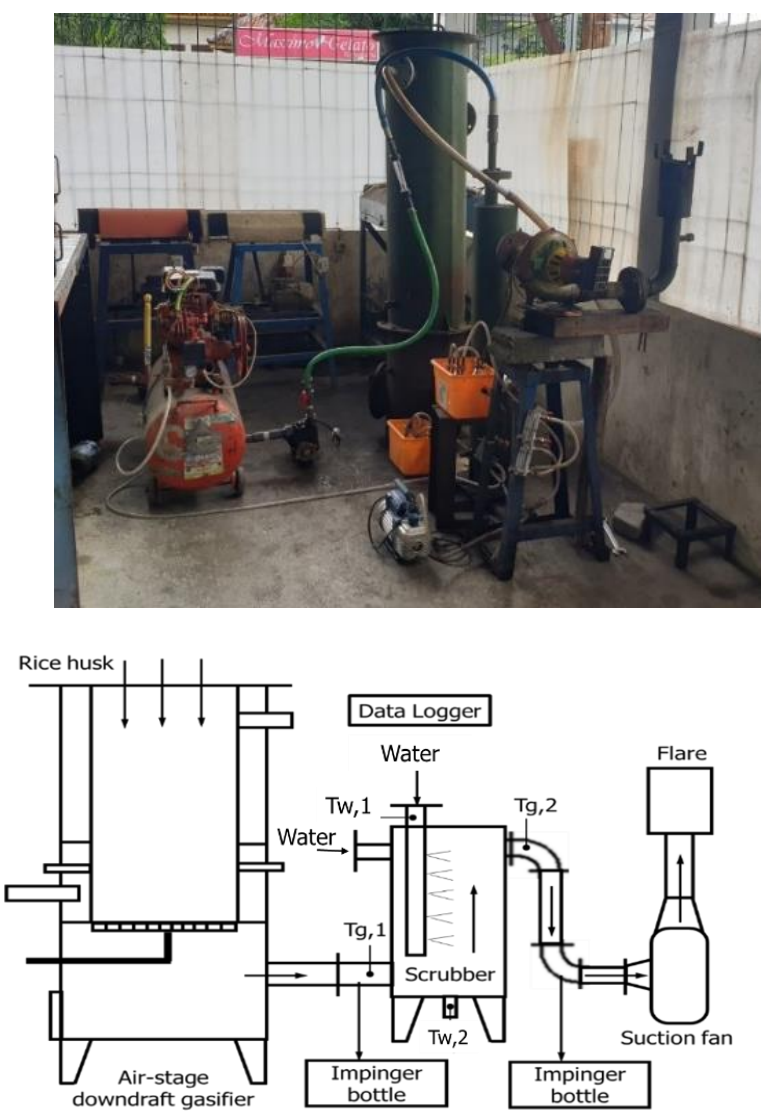

Figure 2 Photograph and schematic diagram of the experimental setup

In the present work, the adsorbent flow rate was maintained at $5 \mathrm{lpm}$. The gasifier was run on the feedstock of rice husk at equivalence ratio of 0.30 . Firstly, the scrubber was tested under three different spray configurations, i.e. cross spray, counter spray, and mixed spray using adsorbent of tap water. The schematic diagrams of spray direction relative to the producer gas flow were presented in Figure 3. The adsorbent sprays perpendicular to producer gas flow in cross spray configuration, parallel but in opposite direction to producer gas flow in counter spray configuration, and combination of cross and counter spray in mixed spray configuration. Secondly, the scrubber was evaluated by changing the water with waste of cooking oil follows by waste of engine lubricant. The selection of water, waste of cooling oil and engine lubricant was based on the availability and accessibility. Those adsorbents can be obtained freely. The selection was also based on the density and specific heat of those adsorbents as shown in Table 1. The density and specific heat of water, cooking oil, and engine lubricant were not very much differ. In this second part, the tests were performed under cross spray configuration with adsorbent flow rate of $5 \mathrm{lpm}$.
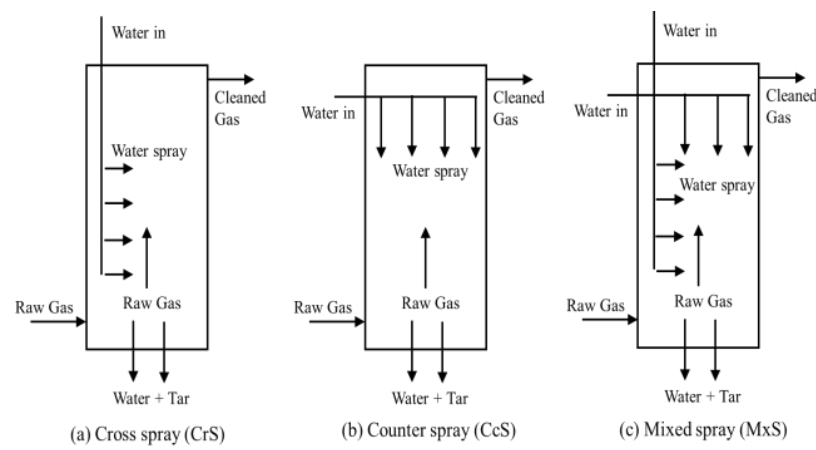

Figure 3 Spray configuration of the scrubber

Table 1 Density and specific heat of the adsorbent [26, 27]

\begin{tabular}{lcc}
\hline \multicolumn{1}{c}{ Adsorbent } & $\begin{array}{c}\text { Specific heat } \\
(\mathbf{k J} / \mathbf{k g} . \mathbf{K})\end{array}$ & Density $\mathbf{( k g / \mathbf { m } ^ { 3 } )}$ \\
\hline Water & 4.18 & 1000 \\
Cooking oil & 1.67 & 840 \\
Engine lubricant & 2.05 & 872.5 \\
\hline
\end{tabular}

The scrubber is evaluated its thermal performance and tar removal efficiency. Thermal performances evaluated are temperature profile of producer gas and adsorbent, log mean temperature different (LMTD), and heat transfer rate (Q) from the producer gas to the adsorbent. Meanwhile, gravimetric tar is sampled before and after the scrubber by impinging bottle method. Producer gas is by-passed to the impinging bottles containing an isopropanol. The producer gas condenses in the bottles and mixes with the isopropanol. The gravimetric tar (mass of the tar in producer gas) is obtained by condensing the isopropanol collected from the impinging bottle in electric oven at a temperature of $50^{\circ} \mathrm{C}$ for 2 hours. The isopropanol evaporates but the tar remains. This remaining tar is weighted to obtain its mass. Once the mass of tar before and after the scrubber are 
obtained, tar removal effectiveness is calculated using Equation (3).

\subsection{RESULTS AND DISCUSSION}

\subsection{An Effect of Spray Configuration on Performance of the Spray Scrubber}

Figure 4 shows temperature profiles of the producer gas and the water at the inlet and outlet of the scrubber during the test. The temperature of the producer gas at inlet and outlet are indicated by Tgi, and Tgo, respectively. Meanwhile, temperature of water at inlet and outlet are indicated using Twi and Two, accordingly. Hot fluid, producer gas, is cooled by the cold fluid, the water. Generally for all flow configurations, temperatures of the producer gas at inlet and outlet of the scrubber rise as increasing time. This is because the temperature at the exit of the gasifier steps up as gasification proceeds. In the scrubber, the gas is cooled and scrubbed by the spray of the water. Heat of the producer gas is absorbed by the water, causes temperature of the gas deceases when leaving the scrubber. Since water absorbs heat from producer gas, the exit temperature of the water is higher than its inlet temperature. Because temperature of the producer gas decreases during the scrubbing, tar in the producer gas condenses and dilutes in the water. Thus, the process leads to remove tar in the producer gas.
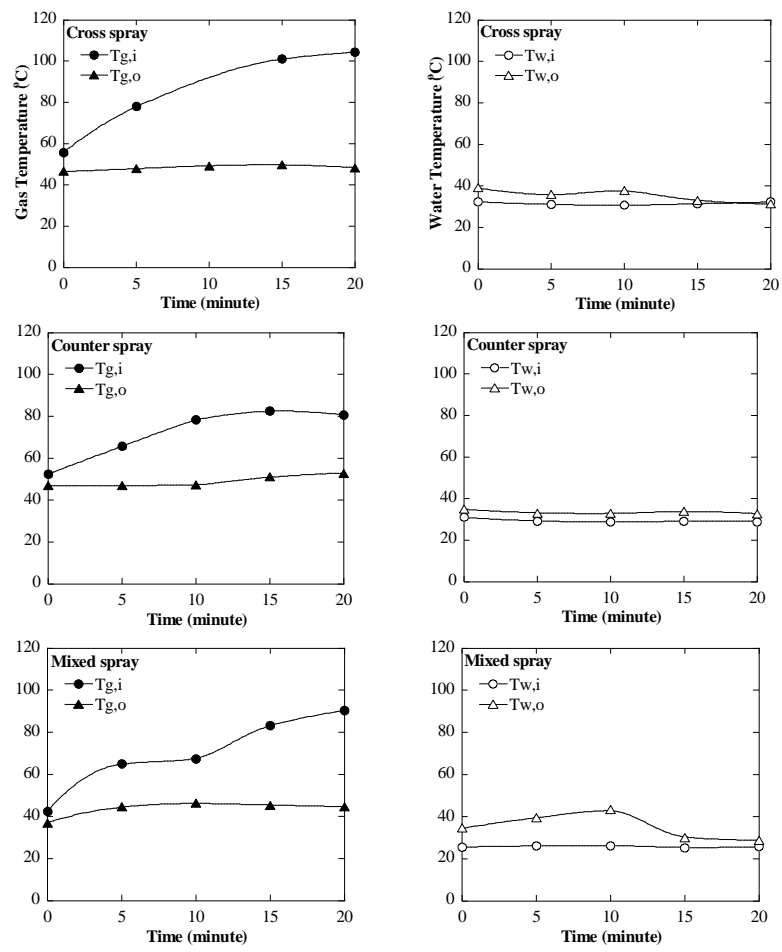

Figure 4 Temperature profile of producer gas and water
Average inlet and outlet temperatures of the producer gas and the water are given in Figure 5. Label 1 in horizontal axis indicates inlet of the producer gas and outlet of the water and vice versa for label 2 (counter flow). For all flow configurations, average temperatures of producer gas reduce after scrubbing and in contrast average temperatures of the water step up after scrubbing. Heat of the producer gas is absorbed by the water during the scrubbing. The different between inlet gas temperature and outlet water temperature and the different between gas exit temperature and water inlet temperature is defined as log mean temperature different (LMTD).

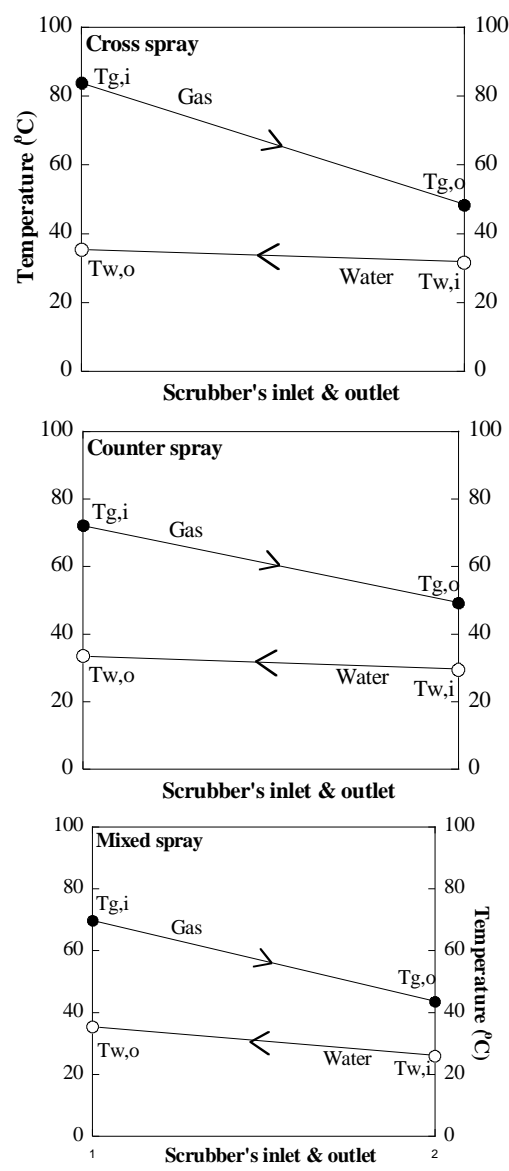

Figure 5 Average temperature of producer gas and water temperature

The LMTDs of the scrubber, heat absorbed by the water, and overall heat transfer coefficient are displayed in Figure 6. The LMTD of the scrubber are $29.8^{\circ} \mathrm{C}, \quad 28.1^{\circ} \mathrm{C}$, and $26.2^{\circ} \mathrm{C}$ for cross flow configuration (CrS), counter flow configuration (CcS), and mixed flow configuration (MXS), correspondingly. The CrS scrubber has the highest LMTD. This is due to the reduction in average gas temperature is the highest in Crs scrubber as can be seen in Figure 5. The LMTD of the water scrubber is the highest among others. The highest LMTD of the CrS scrubber give the 
highest heat transfer from the producer gas to the water. Heat transferred from the producer gas to the water for the CrS is $7.84 \mathrm{~kW}$. Meanwhile for CcS and MxS, the values are $6.86 \mathrm{~kW}$ and $6.19 \mathrm{~kW}$, respectively. Increasing heat transferred causes faster cooling process of the producer gas. This means that the producer gas temperature reaches condensation temperature of the tar faster, thus increasing effectiveness of the scrubbing process.

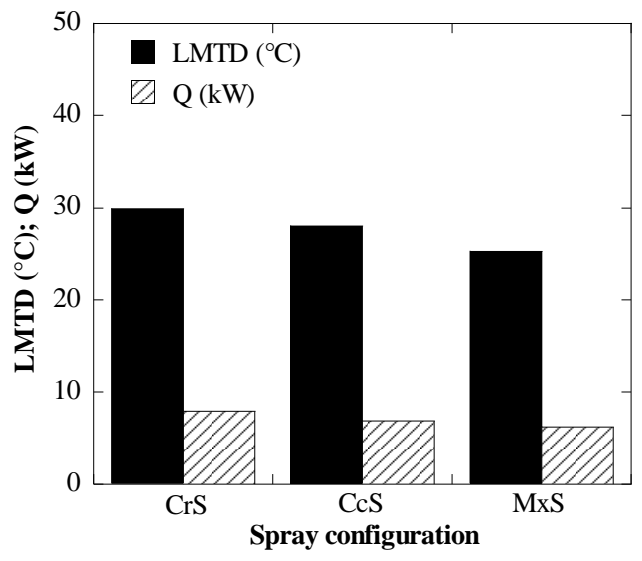

Figure 6 LMTD and heat transfer (Q)

Figure 7 displays tar content before and after scrubber and tar removal efficiency of the scrubber. After scrubbing, tar content of producer gas reduces as the objective of the present work, such that reducing tar content in the producer gas. Cooling and scrubbing of the producer gas by water causes tar in the producer gas condenses and form tar condensate and dilutes in the water. The most effective tar removal is observed for CsS configuration. The effectiveness of the CsS configuration is 0.43 . The highest LMTD and heat transfer in the CsS scrubber results in better cooling and scrubbing process in CsS than in CcS as well as MxS.

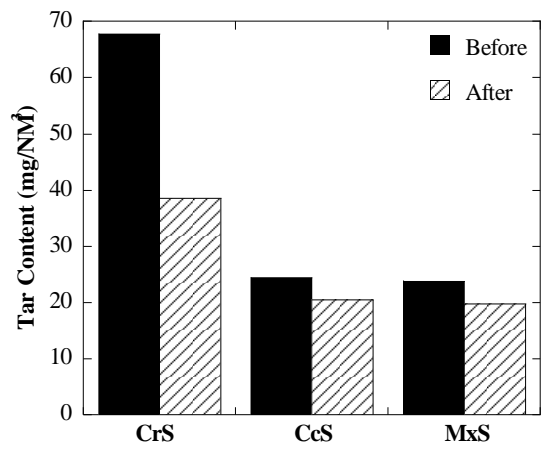

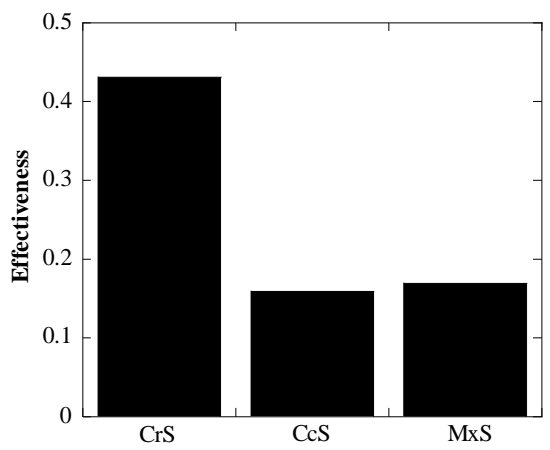

Figure 7 Gravimetric tar and effectiveness of the scrubber

\subsection{An Effect of Adsorbent Material on Performance of the Spray Scrubber}

Figure 8 presents temperature profiles of the producer gas and the adsorbent at the inlet and outlet of the scrubber within 20 minute. Producer gas as hot fluid is cooled by the adsorbent as the cold fluid. In general, producer gas temperatures at inlet and outlet of the scrubber increase as increasing time for all adsorbents. This is because the producer gas temperature at the exit of the gasifier steps up as gasification proceeds. In the scrubber, the gas is cooled and scrubbed by the spray of the adsorbent. Heat of the producer gas is absorbed by the adsorbent, this causes temperature of the gas decreases when leaving the scrubber. Since adsorbent absorbs heat from producer gas, the exit temperature of the adsorbent is higher than its inlet temperature. Due to temperature decreasing in the scrubber, tar in the producer gas condenses and dilutes in the adsorbent. Thus, the process leads to the removal tar in the producer gas.
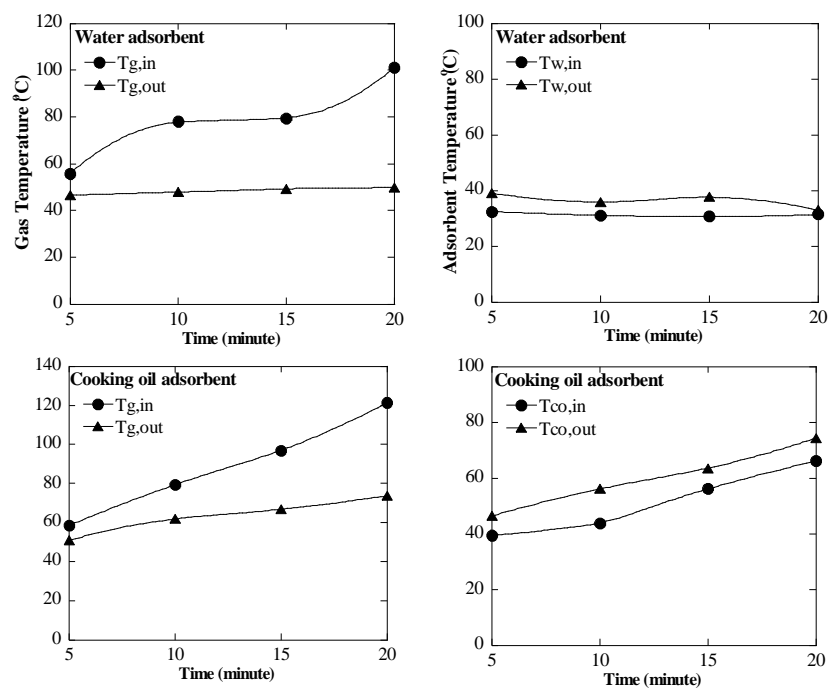

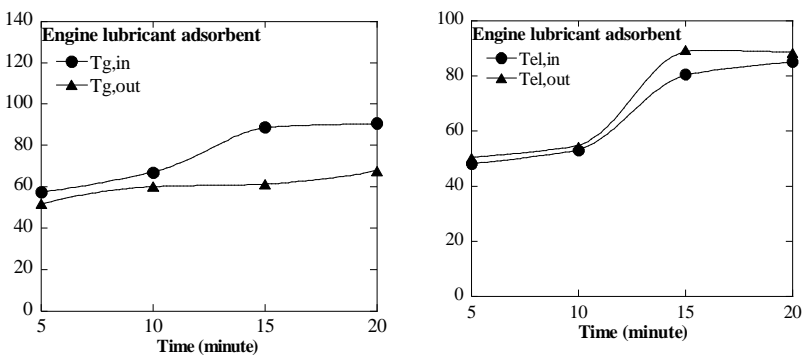

Figure 8 Temperature of producer gas and adsorbent

Meanwhile, average inlet and outlet temperatures of the producer gas and the adsorbent are given in Figure 9. For all adsorbent, average temperatures of producer gas reduce after scrubbing and in contrast average temperatures of the adsorbent increase after scrubbing. Heat of the producer gas is absorbed by the adsorbent during the scrubbing.

The LMTDs of the scrubber and heat absorbed by the adsorbent using adsorbent of water, cooking oil, and engine lubricant at flow rate of $5 \mathrm{lpm}$ are displayed in Figure 10. The LMTD of the scrubber are $25.7^{\circ} \mathrm{C}, 14.0^{\circ} \mathrm{C}$, and $9.8^{\circ} \mathrm{C}$ for water, cooking oil, and engine lubricant, respectively. The LMTD of the water scrubber is the highest among others. The graph in Figure 5 also shows the trend of heat transfer to the adsorbent is similar with the LMTD. Heat transfer rate to the adsorbent decreases as LMTD reduces. The heat transfer rate to the water is the highest among other. This indicates that cooling process of the producer gas is more effective in water scrubber. The reduction in temperature of producer gas is the highest when using water scrubber as can be seen in Figure 9. The heat transfer rates to the adsorbent are $1750 \mathrm{~W}, 1022 \mathrm{~W}$, and $961 \mathrm{~W}$, correspondingly.

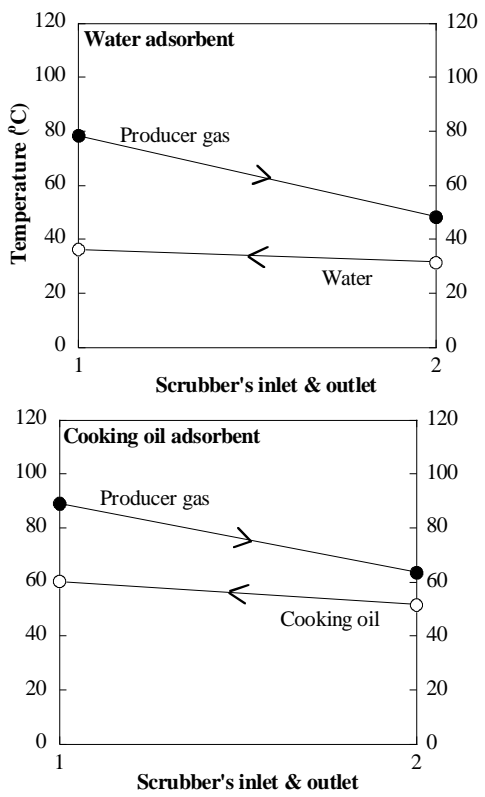

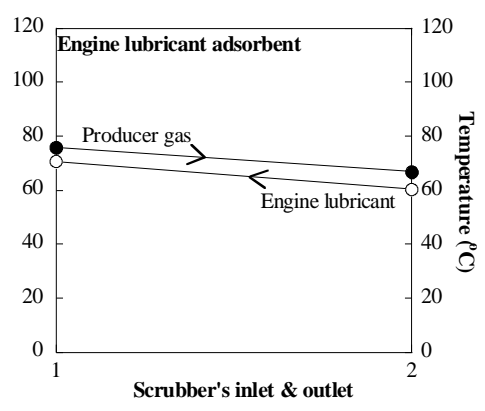

Figure 9 Average temperature of producer gas and adsorbent

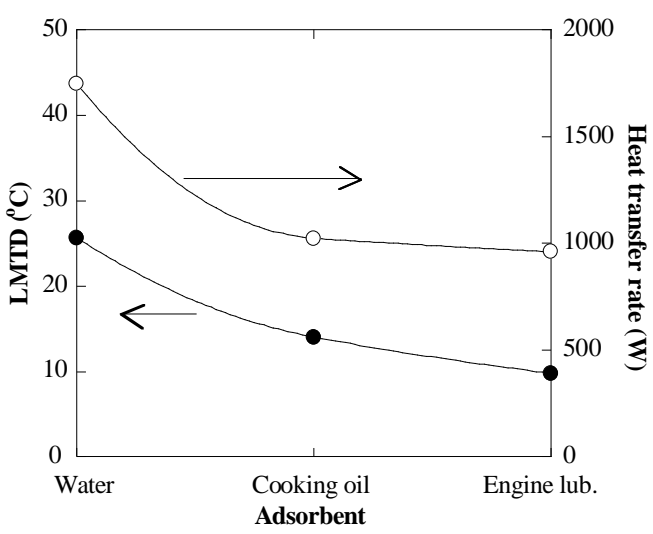

Figure 10 LMTD and heat transfer rate

Figure 11 displays tar content before and after scrubber and tar removal effectiveness of the scrubber using adsorbent of water, cooking oil, and engine lubricant at flow rate $5 \mathrm{lpm}$. After scrubbing, tar content of producer gas reduces at all adsorbent observed. This is due to cooling and scrubbing of the producer gas by adsorbent causes tar in the producer gas condenses and form tar condensate and dilutes in the adsorbent. The most effective tar removal is observed during the use of engine lubricant. The scrubber effectiveness are $0.43,0.12$, and 0.60 for water, cooking oil, and engine lubricant, respectively. Besides cooling effect, the tar removal process is affected by adsorption property of the adsorbent. Although cooling is more effective in water scrubber, hence condensing process also more effective, but the highest scrubber effectiveness is observed in engine oil scrubber. This seems to be due to better adsorption property of engine lubricant than that of water and cooking oil. 

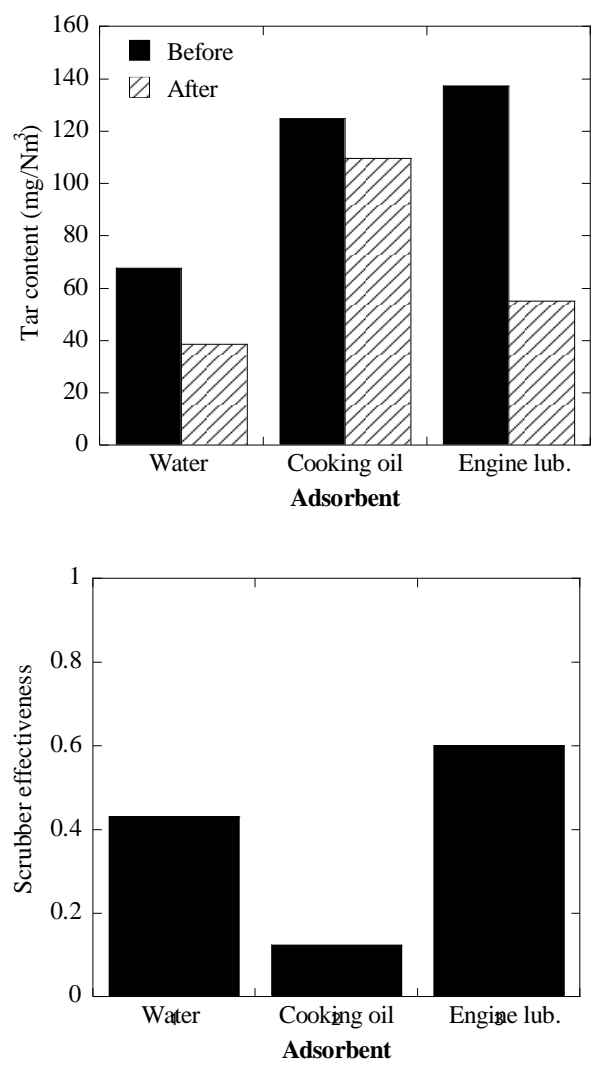

Figure 11 Gravimetric tar and effectiveness of the scrubber

\subsection{CONCLUSION}

Performance of spray scrubber for removing gravimetric tar in producer gas from rice husk gasification is evaluated under three different spray configuration of the adsorbent and by using adsorbent water, waste of cooking oil, and waste of engine lubricant. It can be concluded that the cross spray scrubber (CrS) is the optimum scrubber for tar removal of the producer gas. The CsS scrubber has the highest LMTD, heat transfer, and tar removal efficiency among others. The values are $29.8^{\circ} \mathrm{C}, 7.84$ $\mathrm{kW}$, and 0.60 , accordingly. Adsorption property of the adsorbent plays an important rules in tar removal effectiveness of the scrubber. The removal effectiveness of the scrubber for using adsorbent of water, cooking oil, and engine lubricant are 0.43 , 0.12 , and 0.60 , respectively.

\section{Acknowledgement}

The authors would like to thank DRPM-RISTEK/BRIN, Ministry of Research and Technology/Board of National Research and Innovation of Republic of Indonesia for the financial support through the scheme of Penelitian Dasar Unggulan Perguruan Tinggi (PDUPT) year of 2021 with reference number of SP DIPA-023.17.1.690439/2021.

\section{References}

[1] A. Erkiaga, G. Lopez, M. Amutio, J. Bilbao, M. Olazar. 2014. Influence of Operating Conditions on the Steam Gasification of Biomass in a Conical Spouted Bed Reactor. Chemical Engineering Journal. 237: 259-267.

[2] A. A. P. Susastriawan, H. Saptoadi, Purnomo. 2019. Comparison of the Gasification Performance in the Downdraft fixed-bed Gasifier Fed by Different Feedstocks: Rice Husk, Sawdust, and Their Mixture. Sustainable Energy Technologies and Assessments. 34: 27-34.

[3] Z. Ma, J. Ye, C. Zhao, Q. Zhang. 2015. Gasification of Rice Husk in Downdraft Gasifier. Bio Resources. 10(2): 28882902.

[4] S. J. Yoon, Y. II Sun, Y. K. Kim, J. G. Lee. 2012. Gasification and Power Generation Characteristics of Rice Husk and Rice Husk Pellet using a Downdraft Fixed-bed Gasifier. Renewable Energy. 42: 163-167.

[5] S. Mahapatra \& S. Dasappa. 2014. Experiments and Analysis of Propagation Front Under Gasification Regimes in a Packed Bed. Fuel Processing Technology. 121: 83-90.

[6] N. Striūgas, et al. 2014. An Evaluation of Performance of Automatically Operated Multi-fuel Downdraft Gasifier for Energy Production. Applied Thermal Engineering. 73(1): 1151-1159.

[7] H. Olgun, S. Ozdogan, G. Yinesor. 2011. Results with a Bench Scale Downdraft Biomass Gasifier for Agricultural and Forestry Residues. Biomass and Bioenergy. 35(1): 572580,

[8] F. Guo, Y. Dong, L. Dong, C. Guo. 2014. Effect of Design and Operating Parameters on the Gasification Process of Biomass in a Downdraft Fixed Bed: An Experimental Study. International Journal of Hydrogen Energy. 39(11): 56255633,

[9] F. M. Guangul, S. A. Sulaiman, A. Ramli. 2014. Study of the Effects of Operating Factors on the Resulting Producer Gas of Oil Palm Fronds Gasification with a Single Throat Downdraft Gasifier. Renewable Energy. 72: 271-283.

[10] J.J. Hernández, Guadalupe Aranda-Almansa, A. Bula. 2010. Gasification of Biomass Wastes in an Entrained Flow Gasifier: Effect of the Particle Size and the Residence Time. Fuel Processing Technology. 91 (6): 681-92.

[11] S. Anis \& Z. A. Zainal. 2011. Tar Reduction in Biomass Producer Gas via Mechanical, Catalytic and Thermal Methods: A Review. Renewable and Sustainable Energy Reviews. 15(5): 2355-2377.

[12] P. J. Woolcock \& R. C. Brown R. C. 2013. A Review of Cleaning Technologies for Biomass-derived Syngas. Biomass and Bioenergy. 52.

[13] V. Pallozzi, A. Di Carlo, E. Bocci, M. Carlini. 2018. Biomass and Bioenergy Combined Gas Conditioning and Cleaning for Reduction of Tars in Biomass Gasification. Biomass and Bioenergy. 109: 85-90.

[14] T. A. Milne, R. J. Evans, N. Abatzaglou. 1998. Biomass Gasifier '"Tars"': Their Nature, Formation, and Conversion, NREL/TP-570-2535 Report.

[15] M. Zhai, X. Wang, Y. Zhang, P. Dong, G. Qi, Y. Huang. 2015. Characteristics of Rice Husk Tar Secondary Thermal Cracking. Energy. 93: 1321-1327.

[16] A. Paethanom, P. Bartocci, B.D. Alessandro, M.D. Amico, F. Testarmata, N. Moriconi, K. Yoshikawa, F. Fantozzi. 2013. A Low-cost Pyrogas Cleaning System for Power Generation: Scaling Up from Lab To Pilot. Applied Energy. 111: 1080-1088.

[17] T. Phuphuakrat, T. Namioka, K. Yoshikawa. 2011. Absorptive Removal of Biomass Tar using Water and Oily Materials. Bioresource Technology. 102 : 543-549.

[18] A. G. A. Bhave, D. K. Vyas, J. B. Patel. 2008. A Wet Packed Bed Scrubber-based Producer Gas Cooling-cleaning System. Renewable Energy. 33(8) : 1716-1720.

[19] N. A. Ahmad \& Z. A. Zainal. 2016. Performance and Chemical Composition of Waste Palm Cooking Oil as Scrubbing Medium for Tar Removal from Biomass 
Producer Gas. Journal of Natural Gas Science and Engineering. 32: 256-261.

[20] S. Unyaphan, T. Tarnpradab, F. Takahashi, K. Yoshikawa. 2017. Improvement of Tar Removal Performance of Oil Scrubber by Producing Syngas Microbubbles. Applied Energy. 205: 802-812.

[21] N. Liu, L. Zhang, X. Jia. 2017. The Effect of the Air Water Ratio on Counter Flow Cooling Tower the Effect of the Air Water Ratio on Counter Flow Cooling Tower. Procedia Engineering. 205: 3550-3556.

[22] A. Alkhedhair, Z. Guan, I. Jahn, H. Gurgenci, S. He. 2015. Water Spray for Pre-cooling of Inlet Air for Natural Draft Dry Cooling Towers - Experimental Study. International Journal of Thermal Sciences. 90: 70-78.
[23] S. C. Kranc. 2007. Optimal Spray Patterns for Counterflow Cooling Towers with Structured Packing. Applied Mathematical Modelling. 31: 676-686.

[24] Y. Sun, Z. Guan, H. Gurgenci, K. Hooman, X Li, L. Xia. 2017. Investigation on the Influence of Injection Direction on the Spray Cooling Performance in Natural Draft Dry Cooling Tower. International Journal of Heat and Mass Transfer. 110: 113-131.

[25] Cengel, Y. A., Turner, R. H. Fundamental of Thermal-Fluid Science, E-book.

[26] https://amesweb.info/Materials/Specific-Heat-CapacityLiquid-Fluid.aspx, accessed on 24 August 2021.

[27] https://www.engineeringtoolbox.com/specific-heat-fluidsd_151.html, accessed on 24 August 2021. 